\title{
The Effect of Severe Head Injury on Whole Body Energy Expenditure and Its Possible Hormonal Mediators in Children
}

\author{
D. S. F. MATTHEWS, A. AYNSLEY-GREEN, J. N. S. MATTHEWS, R. E. BULLOCK, \\ B. G. COOPER, AND J. A. EYRE \\ Department of Child Health [D.S.F.M., A.A.-G., J.A.E.], Department of Medical Statistics[J.N.S.M.], and \\ Department of Medicine[B.G.C.], University of Newcastle upon Tyne; and Department of \\ Anaesthesia[R.E.B.], Newcastle General Hospital, Newcastle upon Tyne, United Kingdom
}

\begin{abstract}
This study examines the effects of severe head injury in children on whole body energy expenditure and the mediators that influence this. One hundred five serial measurements of whole body energy expenditure and plasma adrenaline, triiodothyronine, glucagon, cortisol, insulin, and growth hormone concentrations were made in 18 children aged $2-15$ y receiving neurointensive care for severe head injury. Energy expenditure was measured using indirect calorimetry by a modified Douglas bag technique, and hormones were measured by RIA or radioenzymatic assay. Energy expenditure varied markedly between and within children (mean $97 \%$ of predicted, range $60-137 \%$ ) and was significantly lower in the four children with a poor outcome $(p=0.03)$. Within each child there were statistically significant positive relationships between energy expenditure and adrenaline
\end{abstract}

Head injury is the most important cause of mortality and long-term morbidity in children over 1 y of age in the Western world, accounting for $25 \%$ of all deaths between the ages of 5 and 15 y (1). However, little is known of the effects of severe head injury on whole body energy expenditure and the mediators that determine this. Both elevated and depressed levels of energy expenditure may be disadvantageous to the critically injured child. Elevated metabolic rates increase nutritional demands, which, being difficult to meet, result in tissue wasting and an increased susceptibility to infection (2). Of equal importance, depressed metabolic rates are associated with a poor prognosis in critically ill adults (3). A greater understanding of the metabolic changes occurring in critically injured children could give rise to therapeutic interventions to aid management and improve outcome. The aims of the current study, therefore,

Received October 20, 1993; accepted November 11, 1994.

Correspondence and reprint requests: Dr. D. S. F. Matthews, The James Spence Institute of Child Health, The Royal Victoria Infirmary, Queen Victoria Rd., Newcastle upon Tyne NE1 4LP, UK.

Supported by the Scientific and Research Committee of Newcastle Health Authority and by the Medical Research Council (D.S.F.M.). Additional financial support was from The Intensive Care Society, The Buttle Trust, The Mason Medical Foundation, and The Peel Medical Research Trust, and CHILD $(p<0.0001)$, triiodothyronine $(p<0.0001)$, and glucagon $(p<$ 0.0001 ). However, there was evidence that the effect of adrenaline on energy expenditure was attenuated. This may be due to the effects of the cerebral trauma itself on central nervous influences on energy expenditure, to interactions between hormones, or to a global impairment of $\mathrm{O}_{2}$ utilization by the body's tissues. (Pediatr Res 37: 409-417, 1995)
Abbreviations
ISS, injury severity score
GCS, Glasgow coma score
$\mathrm{FiO}_{2}$, proportion of $\mathrm{O}_{2}$ in inspiratory gas
T3, triiodothyronine

were to measure serially whole body energy expenditure in children after severe head injury and to investigate the relationship between energy expenditure and possible hormonal mediators.

\section{METHODS}

Subjects. The study was performed in 18 children who had sustained a severe head injury and were receiving neurointensive care. The mean age was 8.2 y with a range of $2-15 \mathrm{y}$. Sixteen children had isolated head injuries, and two children had other associated injuries. Associated injuries were defined as injuries severe enough to warrant hospital admission in their own right, which is approximately equivalent to an ISS of $\geq 9$ (4). In all cases the head injury was the most serious injury sustained. The criterion for admission to the study was a GCS equal to or less than 8 (5). In children aged less than $4 \mathrm{y}$, the adaptation of the GCS described by James and Trauner (6) was used. The mean GCS was 6 (range 3-8). Neurologic outcome in all the children was scored between 6 and 12 mo after injury using an adaptation of the scales used by Berger et al. (7) in their study of head-injured children and Tasker et al. (8) in their study of pediatric nontraumatic coma. For the purpose of 
analysis, the children were divided into two groups, namely, those in whom outcome was good or moderate and those who died or survived with severe disabilities (9). Further clinical details of the children are given in Table 1. Ethical approval for the study was granted by the Joint Ethics Committee of Newcastle Health Authority and University of Newcastle upon Tyne, and informed written consent was obtained from the parents.

Management. The clinical care of the children remained the responsibility of the admitting neurosurgical and anesthetic tcams. All children were intubated and received elective intermittent positive pressure ventilation with mild hyperventilation, $\mathrm{FiO}_{2}$ 0.3-0.35, with the arterial $\mathrm{PCO}_{2}$ being maintained between 3.5 and $4.5 \mathrm{kPa}$.

The children were sedated with continuous i.v. infusions of fentanyl (mean 3.3, range $0.6-8.4 \mu \mathrm{g} \cdot \mathrm{kg}^{-1} \cdot \mathrm{h}^{-1}$ ); 15 children received a simultaneous infusion of midazolam (mean 110, range 33-310 $\left.\mu \mathrm{g} \cdot \mathrm{kg}^{-1} \cdot \mathrm{h}^{-1}\right)$. All children received muscle relaxants, either pancuronium or vecuronium. Seven children were given dopamine (mean 0.46, range 0.06-0.80 $\left.\mathrm{mg} \cdot \mathrm{kg}^{-1} \cdot \mathrm{h}^{-1}\right)$.

Intravenous crystalloid fluids were administered at maintenance requirements or with mild fluid restriction $(75 \%$ of requirements). Nasogastric feeds of a nutritionally complete formula were commenced $24-48 \mathrm{~h}$ after the injury and increased as toleratcd.

Rectal temperature was monitored using a rectal probe (Mon-a-Therm model 6510, Mallinckrodt, Chesterfield, UK) accurate to $\pm 0.1^{\circ} \mathrm{C}$. All children had a urinary drainage catheter and peripheral arterial catheter inserted.

Serial measurements. Serial measurements of whole body metabolic rate together with arterial plasma concentrations of adrenaline, T3, cortisol, glucagon, insulin, and hGH were made in each child as soon as possible after admission to the intensive care unit and repeated every 6-24 h until the child was no longer receiving neurointensive care. All measurements were made during periods of clinical stability.

Measurement of whole body energy expenditure. Whole body metabolic rate was measured using indirect calorimetry by a modified Douglas bag technique. All children were ventilated with a Servo $900 \mathrm{C}$ ventilator with warmed humidified gases. The inspiratory gases were delivered from a two-block rotameter to ensure thorough mixing of the gases. Samples of the inspiratory and all the expiratory gases were collected into 5- and 100-L metalized gas bags (Signal Instrument Company, Camberley, Surrey, UK), respectively, over an accurately timed period of 10-20 min depending on the minute volume of the child. The bags were then sealed until analysis. One liter of each of the expiratory and inspiratory gases was taken for analysis of $\mathrm{O}_{2}$ and $\mathrm{CO}_{2}$ concentrations.

Inspiratory and expiratory $\mathrm{O}_{2}$ concentrations were measured using a paramagnetic $\mathrm{O}_{2}$ analyzer (Servomex 540A, Servomex, Crowborough, Sussex, UK) modified to analyze discrete 100 -mL gas samples and to give a digital readout. Evaluation of the analyzer showed it to have measurement repeatability of $\pm 0.02 \%$ and linearity of $\pm 0.1 \% \quad \mathrm{O}_{2}$ over a $0-100 \%$ range.

Expiratory $\mathrm{CO}_{2}$ concentrations were measured using an infrared $\mathrm{CO}_{2}$ analyzer (Servomex PA404, Servomex). Evaluation of the analyzer showed it to have measurement repeatability of $\pm 0.03 \%$ and linearity of $\pm 0.14 \% \mathrm{CO}_{2}$ over a $0-5 \%$ range.

The $\mathrm{O}_{2}$ and $\mathrm{CO}_{2}$ analyzers were calibrated immediately before use using $\mathrm{N}_{2}$ as zero and a gravimetrically determined calibration gas, $40.01 \% \mathrm{O}_{2} / 2.00 \% \mathrm{CO}_{2} /$ balance $\mathrm{N}_{2}$, as span gas. Each $100-\mathrm{mL}$ sample of either expiratory or inspiratory gas was dried before analysis by passing it through anhydrous calcium chloride. Gas samples were analyzed in triplicate to ascertain stable results.

The volume of the remaining expired gas was measured using a dry gas meter, DTM-200-4 (International Gas Appa-

Table 1. Clinical details of the 18 head-injured children

\begin{tabular}{|c|c|c|c|c|c|c|c|}
\hline Age $(y)$ & Sex & GCS & Drugs* & $\begin{array}{c}\text { Duration of } \\
\text { study (h) }\end{array}$ & $\begin{array}{c}\text { No. of } \\
\text { measurements }\end{array}$ & $\begin{array}{l}\text { Time of } 1 \mathrm{st} \\
\text { measure } \dagger(\mathrm{h})\end{array}$ & Outcome \\
\hline 3.4 & $F$ & $3+$ & F $1.7-6.7$, M 200-270 & 79 & 7 & 9 & Poor \\
\hline 8.8 & M & 3 & F $2.3, \mathrm{M} 45-180$ & 103 & 9 & 10 & Good \\
\hline 15.6 & $\mathrm{~F}$ & 3 & F 0.9, M $40-75$ & 25 & 3 & 20 & Moderate \\
\hline 4.0 & M & 4 & F 1.2 & 9 & 2 & 7 & Died \\
\hline 10.2 & $\mathrm{~F}$ & 4 & F $2.6-4.3$, M 35-100 & 107 & 10 & 15 & Died \\
\hline 14.0 & M & 4 & F $2.5-3.8$ & 178 & 11 & 10 & Good \\
\hline 6.4 & M & 6 & F $1.1-6.6$, M $130-310$ & 79 & 8 & 9 & Moderate \\
\hline 6.4 & $\mathrm{~F}$ & $6 \div$ & $\mathrm{F} 2.0-4.0, \mathrm{M} 80$ & 55 & 6 & 11 & Good \\
\hline 12.0 & M & 6 & F $0.6-1.9$, M 50-75 & 103 & 9 & 9 & Moderate \\
\hline 8.6 & M & 7 & F 3.3-5.0, M 33-100 & 41 & 5 & 10 & Died $\S$ \\
\hline 9.0 & M & 7 & F 4.9, M 165-230 & 5 & 2 & 14 & Good \\
\hline 11.4 & M & 7 & F 1.6, M 65-95 & 85 & 7 & 11 & Good \\
\hline 11.5 & M & 7 & F $4.4-5.8$, M 85-115 & 83 & 8 & 12 & Moderate \\
\hline 2.4 & $\mathrm{~F}$ & 8 & $\mathrm{~F} 6.4, \mathrm{M} 170$ & 18 & 3 & 36 & Good \\
\hline 2.5 & $\mathrm{M}$ & 8 & F $2.1-8.4, M ~ 85-105$ & 61 & 5 & 14 & Moderate \\
\hline 3.5 & M & 8 & F 2.2 & 49 & 3 & 25 & Good \\
\hline 8.6 & $\mathrm{M}$ & 8 & $\mathrm{~F} 2.0, \mathrm{M} 40$ & 25 & 3 & 26 & Good \\
\hline 9.9 & M & 8 & F $2.5-5.0$, M 50-100 & 28 & 4 & 12 & Good \\
\hline
\end{tabular}

$* \mathrm{~F}=$ fentanyl $\left(\mu \mathrm{g} \cdot \mathrm{kg}^{-1} \cdot \mathrm{h}^{-1}\right), \mathrm{M}=$ midazolam $\left(\mu \mathrm{g} \cdot \mathrm{kg}^{-1} \cdot \mathrm{h}^{-1}\right)$.

$\dagger$ Time of 1 st measurement $=$ time after injury of first measurement.

$\$$ Associated injuries.

$\S$ Child died 5 wk after injury from a subarachnoid hemorrhage after a good neurologic recovery. 
ratus Ltd., Camberley, Surrey, UK). Evaluation of the dry gas meter and gas bag system gave a gas volume recovery of $99-102 \%$, over a volume range of $50-90 \mathrm{~L}$ of gas. Room temperature and barometric pressure were recorded and the saturated expired gas volume was converted to standard temperature and pressure, dry conditions.

Seven children were intubated with cuffed endotracheal tubes and 11 children with uncuffed endotracheal tubes. Possible leakages of expired gases around uncuffed endotracheal tubes may lead to errors in estimation of expired gas volume. The potential error was assessed by measuring the $\mathrm{CO}_{2}$ concentration in the child's oropharynx and comparing it with the ambient $\mathrm{CO}_{2}$ concentration. The limit of detection for a difference in $\mathrm{CO}_{2}$ compared with ambient was $0.07 \%$. The method has been compared with the quantitative method of Knauth and Baumgart (10), and no difference in the ability to detect significant air leaks has been found (11). In only 14 of the 105 total measurements was there evidence of a leakage of expired gas. Inasmuch as any leakage has been shown to be small (about 2.5\%) (10), the 14 observations were not excluded from subsequent analysis, although they were distinguished to allow identification (see Fig. 2).

Twenty-four-hour urine collections were made, and the total volume of urine was measured. Aliquots of $5 \mathrm{~mL}$ were stored at $-40^{\circ} \mathrm{C}$ for later determination of total $\mathrm{N}$ content by the Kjeldahl method (12) using an automated Kjeltac 1026 distillater (Perstorp Analytical Ltd., Basinstoke, UK) with back titration into standard boric acid.

Calculations. Whole body metabolic rate was calculated using the following equations:

$$
\begin{aligned}
\mathrm{VO}_{2} & =\mathrm{VE}\left[\frac{\left(1-\mathrm{FeO}_{2}-\mathrm{FeCO}_{2}\right)}{1-\mathrm{FiO}_{2}} \times \mathrm{FiO}_{2}-\mathrm{FeO}_{2}\right] \\
\mathrm{VCO}_{2} & =\mathrm{VE} \times \mathrm{FeCO}_{2} \quad \text { (using Haldane transformation) } \\
\mathrm{EE} & =16.501 \mathrm{VO}_{2}+4.631 \mathrm{VCO}_{2}-9.09 \mathrm{~N}\left(\mathrm{~kJ} \cdot \mathrm{min}^{-1}\right) \quad(13)
\end{aligned}
$$

where $\mathrm{VO}_{2}=\mathrm{O}_{2}$ consumption in $\mathrm{L} \cdot \mathrm{min}^{-1}, \mathrm{VE}=$ expired volume in $\mathrm{L} \cdot \mathrm{min}^{-1}$ at standard temperature and pressure, dry conditions, $\mathrm{FeO}_{2}=$ proportion of $\mathrm{O}_{2}$ in mixed expiratory gas, $\mathrm{FeCO}_{2}=$ proportion of $\mathrm{CO}_{2}$ in mixed expiratory gas, $\mathrm{VCO}_{2}$ $=\mathrm{CO}_{2}$ production in $\mathrm{L} \cdot \mathrm{min}^{-1}, \mathrm{EE}=$ energy expenditure in $\mathrm{kJ} \cdot \min ^{-1}$ and $\mathrm{N}=\mathrm{N}$ excretion in $\mathrm{g} \cdot \min ^{-1}$.

Validation of method for the measurement of whole body metabolic rate. The complete indirect calorimetry system was evaluated using $\mathrm{N}_{2}$ and $\mathrm{CO}_{2}$ dilution techniques as described by Westenskow et al. (14). $\mathrm{O}_{2}$ consumption was simulated by infusing a gravimetrically determined quantity of $\mathrm{N}_{2}$ to dilute the expired $\mathrm{O}_{2}$ content, and $\mathrm{CO}_{2}$ production was simulated by infusing a gravimetrically determined quantity of $\mathrm{CO}_{2}$. A total of 55 experiments were performed. The range of tidal volumes (3.5-9.0 L), ventilator rates $\left(15-20 \mathrm{~min}^{-1}\right), \mathrm{Fio}_{2}(0.3-0.6)$, and simulated $\mathrm{O}_{2}$ consumption and $\mathrm{CO}_{2}$ production $(75-250 \mathrm{~mL}$ $\min ^{-1}$ ) were chosen to simulate the likely clinical conditions encountered. At an $\mathrm{Fio}_{2}$ of 0.3 , the mean $\mathrm{O}_{2}$ consumption recovery was $99.9 \%\left(\mathrm{SD} \pm 2 \%\right.$ ) and the mean $\mathrm{CO}_{2}$ production recovery was $99.4 \%(\mathrm{SD} \pm 2 \%)$.
The repeatability of measurements of whole body metabolic rate was assessed in three children, two gas collections being performed sequentially in each child. The percentages of relative errors for whole body metabolic rate were $0.5,0.4$, and $2 \%$.

Units of measurement for energy expenditure. To enable comparisons to be made between children with head injury and normal resting children, energy expenditure was expressed as a percentage of the basal metabolic rate predicted on the basis of age, sex, and weight of normal children (15). The reference range for normal resting children is $85-115 \%$ of predicted whole body metabolic rate, with $95 \%$ of measurements from normal children lying within this range. Body weight was determined in each child by sitting balance scales (Weylux model 824/890, Morduc Bros., Newcastle upon Tyne, UK) after discontinuing neurointensive care.

Energy expenditure was also expressed in terms of kilograms of fat-free mass. This enabled the relationship between hormone concentrations and the energy expenditure of the metabolically active tissues of the body to be explored. Fat-free mass was calculated from the child's bioelectrical impedance, measured using a Holtain Body Composition Analyser (Holtain Ltd., Crosswell, Dyfed, UK) and the child's height and age. Fat-free mass was calculated from the equations of Schaefer et al. (16).

Measurement of plasma hormone concentrations. A 2-mL blood sample was taken from the indwelling peripheral arterial catheter at the end of each gas collection. Blood for plasma glucagon assay was collected into a tube containing aprotinin, and the remaining sample was collected into a heparinized tube. Sample tubes were stored on ice during collection, and plasma for hormone assays was immediately separated and stored at $-80^{\circ} \mathrm{C}$. Plasma T3, insulin, cortisol, and glucagon concentrations were determined by RIA (17). hGH concentrations were determined using a radioimmunometric assay. A double isotope radioenzymatic method was used for the assay of plasma adrenaline concentrations (18).

Statistical analysis. Adrenaline, insulin, and hGH had skewed distributions and were logged before analysis.

The data set is a mixture of cross-sectional and longitudinal data. To examine the between-child and within-child relationships between different variables, the data were analyzed using multilevel models (19) fitted using the ML3 program (20). This methodology is related to multiple regression and produces similar regression coefficients and standard errors, but allows each child to contribute different numbers of observations. Results are available for within- and between-child analyses, due to centering of explanatory variables, and these will be discussed scparately.

For graphical presentation, the within-child relationships between energy expenditure and hormonal concentrations were displayed by calculating the mcan for each variable for each child and expressing every observation in terms of the residual from that child's mean. By taking the residuals, the betweenchild variation was removed, and the longitudinal component of the data could be displayed. 


\section{RESULTS}

One hundred five serial measurements of energy expenditure and hormonal concentrations were performed in the 18 children. The median number of measurements per child was six (range two to 11). The median duration of each study was 58 h (range 5-178 h). In 11 children $(61 \%)$ the first measurement was performed within $12 \mathrm{~h}$ after injury. The median time between injury and the first measurement in all 18 children was $11.7 \mathrm{~h}$ (range 7-36 h). Fat-free mass was measured in 15 children. The equipment was unavailable for this measurement in three children. Twelve children received enteral nutrition in 41 of the total 105 measurements providing a mean of $61 \%$ of their measured energy expenditure (range 27-106\%). When comparing the energy expenditure of fed $(n=41)$ versus unfed $(n=64)$ observations, the mean energy expenditure of the fed children was $98.7 \%$ of predicted, and the mean energy expenditure of the unfed children was $96 \%$ of predicted (unpaired $t$ test $p=0.29,95 \%$ confidence interval for difference -7.4 , 2.2). Thus, there was no evidence of an effect of enteral feeding on energy expenditure. Further details of the results are given in Table 1.

Whole body energy expenditure after severe head injury. Figure 1 shows whole body energy expenditure against time after the head injury, energy expenditure being expressed as a percentage of the predicted. Energy expenditure was within the reference range ( $85-115 \%$ of predicted) for 86 measurements $(82 \%)$, elevated for four measurements (4\%) from four children, and below the reference range for 15 measurements (14\%) from five children. Sixty-six percent of the depressed values came from the only two children who died acutely.

There was no evidence of a relationship between percentage predicted energy expenditure on admission and GCS ( $p=$ $0.216, r=-0.306$ ).

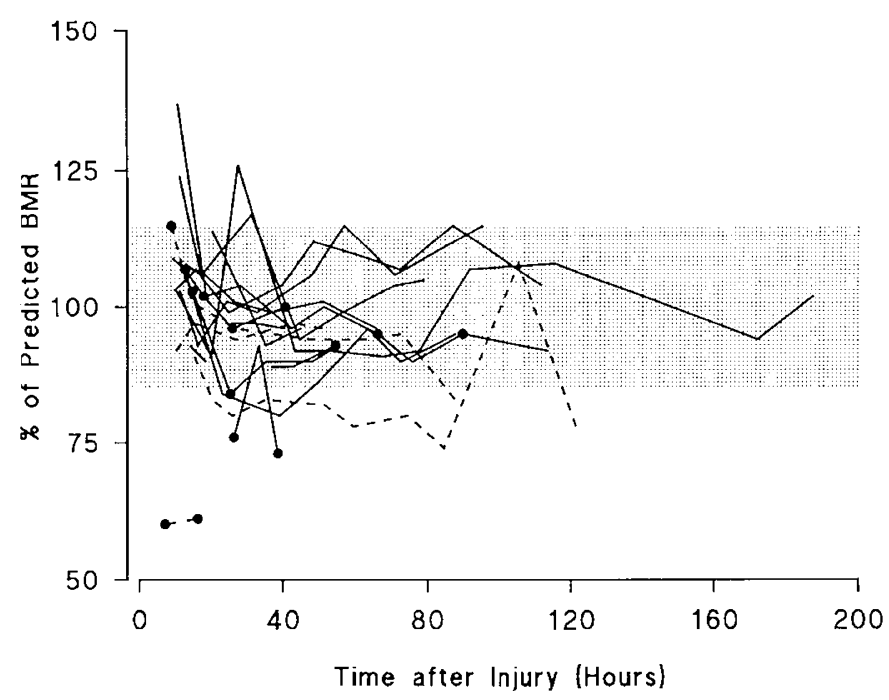

Figure 1. Time after injury vs percentage predicted basal metabolic rate $(B M R)$. Each line represents the serial measurements obtained from each child. The solid lines represent the children with a good outcome and the dashed lines the children with a poor outcome. The closed circles show observations with possible leakage of expired gas around the endotracheal tube. The shaded area in each graph represents the reference range for normal resting children.
Mean percentage predicted energy expenditure was significantly lower in the four children who had a poor outcome ( $84.1 \%$ of predicted) than in the 14 children with a moderate or good outcome (97.8\% of predicted) (randomization test, $p=$ $0.03)$.

Hormonal response after severe head injury and relationship with GCS. The profiles of each hormone over the first 120 $\mathrm{h}$ after injury together with reference ranges for normal resting adults or children (T3 and hGH) are shown in Figure $2(21,22)$. The correlations of initial hormone concentrations with GCS are given in Table 2 .

When compared with reference values for normal resting adults or children, adrenaline and glucagon were elevated, cortisol was mildly elevated initially, and $\mathrm{T} 3$ levels were depressed. Both insulin and hGH were highly variable after head injury.

Initial levels of log adrenaline, glucagon, and log insulin showed a significant negative correlation with GCS, indicating that the most severely injured children had the highest adrenaline, glucagon, and insulin levels.

There were no statistically significant differences in plasma hormone concentrations between children with a poor outcome and children with a moderate or good outcome.

In conclusion, the children were not hypermetabolic after head injury despite elevated concentrations of adrenaline and glucagon. Therefore, the relationships between energy expenditure and hormonal concentrations were examined to determine which hormones had significant effects on energy expenditure. The within-child relationships and between-child relationships are discussed separately.

Within-child relationship between energy expenditure and possible hormonal mediators. The within-child relationships between energy expenditure expressed per $\mathrm{kg}$ of fat-free mass and its possible mediators are shown in Figure 3. Using multilevel modeling, statistically significant positive relationships were found between energy expenditure and log adrenaline $(p=0.0001)$, T3 $(p<0.0001)$, glucagon $(p<0.0001)$, and cortisol $(p=0.03)$. Energy expenditure was not significantly related with $\log$ insulin or $\log$ hGH concentrations ( $p=$ $0.27, p=0.57$, respectively). Further details of the results of the statistical analysis are shown in Table 3.

In normal subjects, energy expenditure increases with temperature. In the study there was a statistically significant positive relationship between energy expenditure (per $\mathrm{kg}$ of fatfree mass) and temperature $(p<0.0001)$ within each child (Fig. 4). Therefore, temperature was included as a covariate in the multilevel model to allow for its effect on the relationship between energy expenditure and each hormone. Log adrena-

Table 2. Relationship of initial hormone concentrations with GCS

\begin{tabular}{lcc}
\hline \multicolumn{1}{c}{ Hormone } & Correlation coefficient & $p$ value \\
\hline Log adrenaline & -0.613 & $<0.01$ \\
T3 & -0.382 & 0.13 \\
Glucagon & -0.564 & 0.02 \\
Cortisol & 0.022 & 0.94 \\
Log insulin & -0.530 & 0.04 \\
Log hGH & -0.205 & 0.42 \\
\hline
\end{tabular}



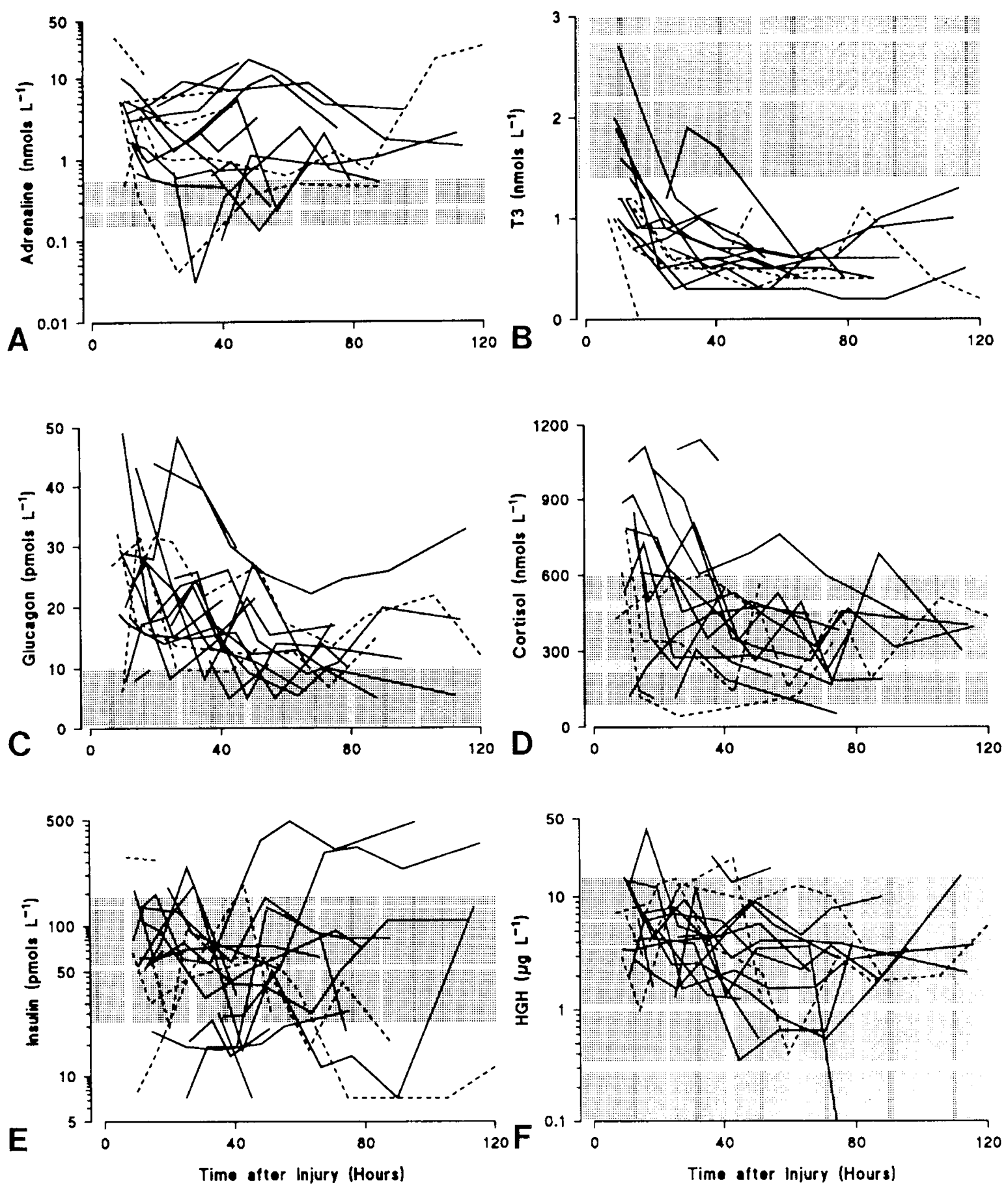

Figure 2. Time after injury vs plasma hormone concentrations. Shown are time after injury vs adrenaline $(A)$, T3 $(B)$, glucagon $(C)$, cortisol $(D)$, insulin $(E)$, and hGH $(F)$. The shaded areas in $B$ and $F$ represent the reference ranges for normal resting children (aged $6-10 \mathrm{y}$ in $B$ ). The shaded areas in the remaining graphs rcpresent the reference ranges for normal resting adults. Adrenaline, insulin, and hGH are shown on log scales.

line, T3, and glucagon still had significant positive effects on energy expenditure ( $p=0.004, p=0.0001$, and $p<0.0001$, respectively), but there was no evidence for an effect of cortisol $(p=0.16)$.

Interhormonal interactions may have effects on energy expenditure. Thus, catecholamines influence the release, metabolism, and response to $\mathrm{T} 3$, whereas $\mathrm{T} 3$ may influence the peripheral response to catecholamines. To ascertain whether the hormones found to have significant positive relationships with energy expenditure were independent of each other, log adrenaline, T3, and glucagon were included as covariates in a multilevel model with energy expenditure. Log adrenaline and T3 were found to have independent statistically significant positive relationships with energy expenditure within each child ( $p=0.001, p=0.003$, respectively). The positive relationship of glucagon with energy expenditure was not statistically significant $(p=0.06)$.

Between-child relationship between energy expenditure and possible hormonal mediators. Details of the analysis of the between-child relationships of energy expenditure (per $\mathrm{kg}$ 

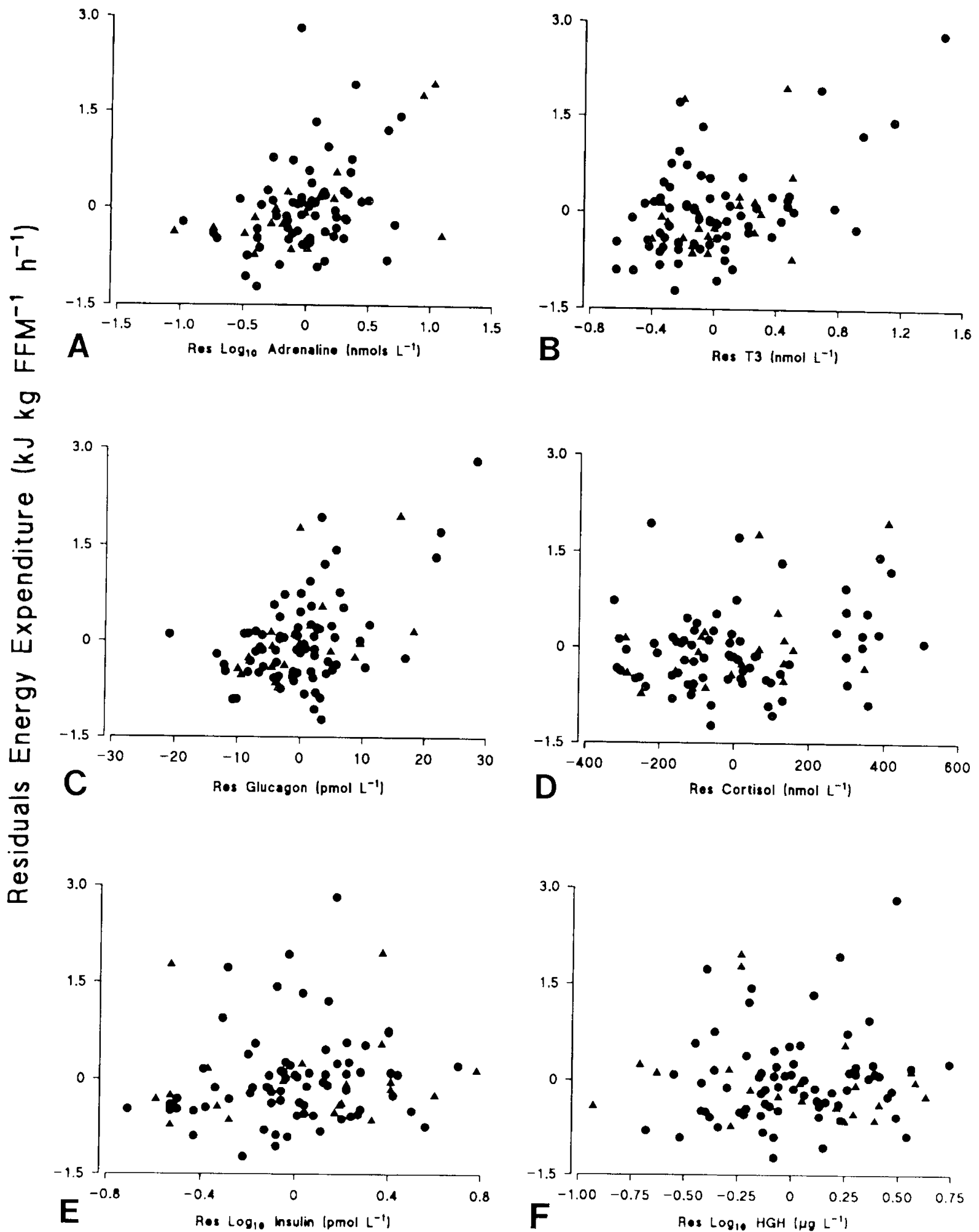

Figure 3. Within-child relationships between plasma hormone concentrations and energy expenditure. Each graph shows the residuals (Res) from the mean for both energy expenditure [per kg of fat-free mass $(F F M)$ ] and hormone concentrations. $A, \log _{10}$ adrenaline; $B, T 3 ; C$, glucagon; $D$, cortisol; $E, \log _{10}$ insulin; and $F, \log _{10} \mathrm{hGH}$. The circles represent observations made on children with a good outcome and the triangles the observations on children with a poor outcome.

of fat-free mass) and possible mediators using multilevel models are shown in Table 3.

Although energy expenditure had a significant negative relationship with $\log$ adrenaline $(p=0.02)$ when comparing between children, this was abolished after allowing for the effect of age ( $p=0.34$ ) on the relationship. Surprisingly, there was no cvidence for a significant positive relationship between energy expenditure and log adrenaline.

There was a significant positive relationship between energy expenditure and $\log \mathrm{hGH}(p=0.001)$ but this was abolished 
Table 3. Details of analysis by multilevel modeling

\begin{tabular}{lccc}
\hline \multicolumn{1}{c}{ Hormone } & Reg. coeff.* & \multicolumn{1}{c}{ SE } & \multicolumn{1}{c}{$p$ value } \\
\hline Within-child relationships for cnergy expenditure & \\
(per kg of fat-free mass) and hormone concentrations & \\
Log adrenaline & 0.71 & 0.19 & 0.0001 \\
T3 & 0.84 & 0.18 & $<0.0001$ \\
Glucagon & 0.04 & 0.009 & $<0.0001$ \\
Cortisol & 0.0008 & 0.0003 & 0.03 \\
Log insulin & 0.28 & 0.25 & 0.27 \\
Log hGH & 0.13 & 0.23 & 0.57 \\
Betwcen-child relationships of energy expenditure & \\
(per kg of fat-free mass) and hormone concentrations & \\
Log adrenaline & -2.5 & 1.1 & 0.02 \\
T3 & -0.96 & 2.0 & 0.63 \\
Glucagon & -0.10 & 0.06 & 0.10 \\
Cortisol & -0.004 & 0.003 & 0.20 \\
Log insulin & -0.75 & 1.5 & 0.62 \\
Log hGH & 4.9 & 1.4 & 0.001 \\
\hline
\end{tabular}

$*$ Reg. coeff $=$ regression coefficient.

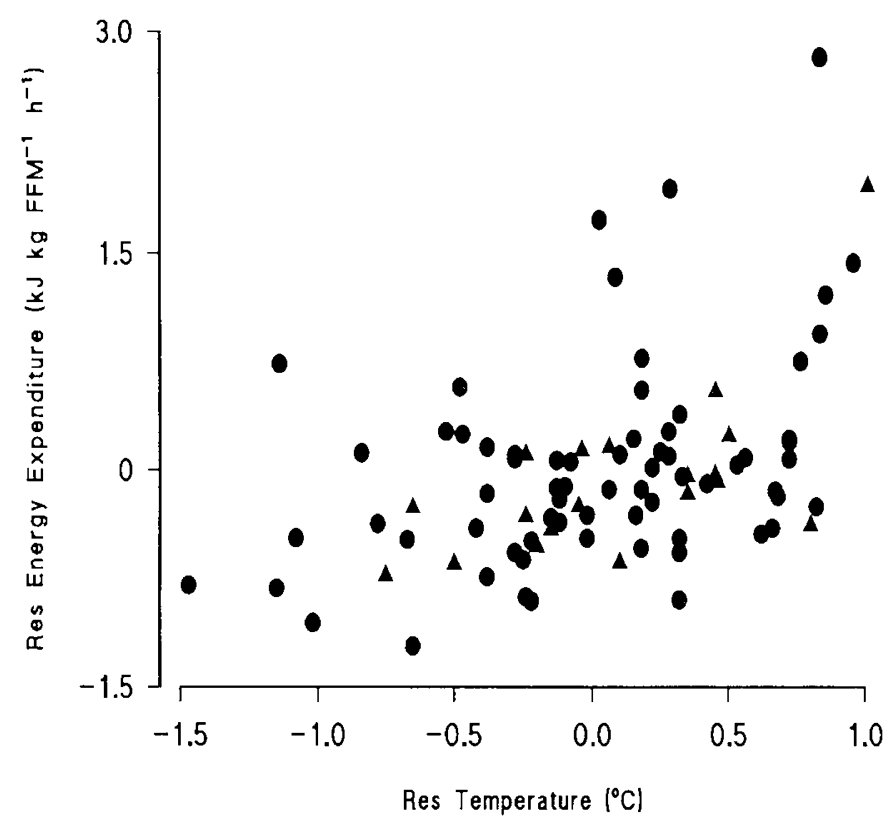

Figure 4. Within-child relationship between core temperature and energy expenditure. The graph shows the residuals (Res) from the mean for both energy expenditure [per $\mathrm{kg}$ of fat-frec mass $(F F M)$ ] and rectal temperature.

when allowing for the effect of age $(p=0.78)$. There was no evidence of a relationship between energy expenditure and glucagon $(p=0.10)$, T3 $(p=0.63)$, cortisol $(p=0.20)$, or $\log$ insulin concentrations $(p=0.62)$.

\section{DISCUSSION}

To the best of our knowledge, this is the first study to describe serial measurements of energy expenditure and possible hormonal mediators in children with critical head injuries. Of particular interest, adrenaline was shown to have a stimulatory effect on energy expenditure and was found to be significantly elevated in these injured children. It is a paradox, therefore, that the children were not hypermetabolic.
Although studies of critically injured adults without a head injury and critically ill postoperative ventilated adults show energy expenditure to be highly variable, the mean energy expenditure lies within the reference range $(23,24)$. However, in adults with a severe head injury, most studies show an increase in energy expenditure that varies up to $160 \%$ of predicted (25), suggesting that adults mount a marked hypermetabolic response to head injury. Although there are few studies of energy expenditure after trauma in children, the results imply a similar hypermetabolic response to head injury (26). However, these studies include unparalyzed and unsedated patients $(25,26)$. The increase in energy expenditure observed may simply be the result of the high incidence of muscle spasm and hypertonicity that is likely to occur in patients with head injuries but not in patients with extracranial injuries.

The measured metabolic rate in the present series of patients was not elevated compared with predicted values. All the patients were sedated and paralyzed. This finding would support the conclusion that the previous findings of a hypermetabolic state may simply reflect differences in management.

However, there is an inherent problem in assessing whether patients receiving intensive care are hyper- or hypometabolic, and this relates to the choice of a suitable comparative "normal" group. The reference range used in this study was derived from children in a resting, spontaneously breathing state. The effects of neurointensive care, including intermittent positivepressure ventilation, muscle relaxants, and sedative drugs, tend to reduce the energy demands of the body $(27,28)$. However, a marked hypermetabolic response is unlikely to be masked by these effects.

The brain is involved in mediating the stress response to injury and, thus, patients with head injuries might be predicted to have a pattern of response that is substantially different from that of patients with extracranial injury alone. The relationship between energy expenditure and possible hormonal mediators has therefore been considered in detail in this group of children.

The plasma concentration of glucagon was elevated in all children in the first $40 \mathrm{~h}$ after injury. There was a negative relationship between glucagon and GCS, indicating that the most severely injured children had the highest glucagon concentrations. To the best of our knowledge, this relationship has not been described before.

The finding of a significant positive relationship between energy expenditure and glucagon within each child was initially surprising. Glucagon is a catabolic hormone that has its major effects on the liver resulting in an increase in hepatic metabolic rate (29). Because the liver accounts for about 30\% of total energy expenditure in children (30), an increase in hepatic metabolic rate may influence ovcrall metabolic rate. One report of a glucagon infusion in one normal adult showed a $14 \%$ increase in whole body $\mathrm{O}_{2}$ consumption (31).

Over $85 \%$ of values of $\mathrm{T} 3$ were below the reference range for normal children. One possible explanation is a direct inhibitory effect of cerebral trauma on the hypothalamicpituitary region reducing thyroid-relcasing hormone and TSH output. Another possibility is that these lowered T3 concentra- 
tions represent the euthyroid sick syndrome that comprises normal TSH, normal or low thyroxine, and low T3. This has been documented previously in critically ill children (32). It was once felt that the euthyroid sick syndrome was a physiologic adaptive mechanism limiting hypermetabolism, but this seems an unlikcly explanation for a condition whose severity has been shown to have a close association with a poor outcome (33).

There was a significant positive relationship between T3 and energy expenditure within each child that persisted after allowing for the effects of temperature and hormonal interactions. This was a surprising finding because, although the positive influence of T3 on energy expenditure is wcll documented, its major effect is a long-term one mediated via nuclear receptors (34). However, there is evidence for a rapid onset, short-lived effect of T3 on energy expenditure (35), which may explain the acute relationship found between $\mathrm{T} 3$ and energy expenditure.

For all children, $82 \%$ of plasma adrenaline concentrations were elevated, some to more than 50 times the upper reference limit. However, $96 \%$ of measurements of energy expenditure fell within or bclow the reference range for normal children. There was a negative relationship betwcen plasma adrenaline concentration and GCS, indicating that the children with the highest plasma adrenaline concentrations were the most severely injured children, and yet the children with poor outcomes had significantly lower encrgy expenditures than children with good or moderate outcomes. The only two children who died acutely had the lowest energy expenditures and very clevated catecholamine levels. Although, as may be anticipated, there was a positive association between adrenaline concentration and encrgy expenditure within each child, there was no evidence of a positive relationship when comparing between children. These results indicate that although adrenaline is a hormonal mediator of energy expenditure its effect may be decreased in critically head-injured children.

There are several possible mechanisms that may explain this finding. Desensitization of stimulatory $\beta_{1}$ - or $\beta_{3}$-adrenergic receptors may result in a reduced response to catecholamines possibly mediated by the effects of decreased circulating levels of T3 $(36,37)$. Alternatively, the activation of inhibitory $\alpha_{2}$ receptors may reduce the overall response of the cell to the stimulatory $\beta$ effects (38). Another possible mechanism for the decreased response to adrcnaline is that the tissues arc unable to respond to positive stimuli owing to impaired utilization of $\mathrm{O}_{2}$. This has been described globally in septic shock (39).

There is further support for a modified effect of adrenaline on energy expenditure after critical head injury. A wellcontrolled study by Hadfield et al. (40) of 13 ventilated, paralyzed adults with severe head injury showed that mean energy expenditure fell within the normal range, and plasma adrenaline concentrations were elcvated compared with both healthy controls and extracranially injured adults, indicating that head injury per se may lead to an attenuation of the response of whole body energy expenditure to adrenaline.

Further studies aiming to clucidate the mechanisms underlying the modified response to hormonal mediators are necessary. This is not an esoteric discussion, inasmuch as it has been demonstrated in the present report and in studies by other authors that depressed levels of energy expenditure are associated with a poor prognosis (3). The elucidation of the mechanisms underlying the relationship between energy expenditure and its hormonal mediators would give greater understanding of the whole body response to head injury in children and potentially highlight therapeutic interventions to aid management and improve outcome.

Acknowledgments. The authors thank the medical and nursing staff of the intensive carc unit, and the consultant neurosurgeons who allowed us to study their patients. We acknowledge the assistance of Professor K. G. M. M. Alberti, L. Ashworth, A. Burnett, A. McGann, S. Turner, Dr. M. Watson of Newcastle University; Professor S. Bloom and Dr. M. Ghatei of Hammersmith Hospital, London; and M. Ashby and Professor M. Brown of the Department of Clinical Pharmacology, Cambridge, for their help with the assays performed in this study.

\section{REFERENCES}

1. Sharples PM, Storey A, Aynsley-Grecn A, Eyre JA 1990 Avoidable factors contributing to death of children with head injury. BMJ 300:87-91

2. Dionigi R, Gnes F, Bonera A, Dominioni L 1979 Nutrition and infection. J Parenter Enteral Nutr 3:62-68

3. Wilson RF, Christensen C, I.eBlanc LP 1972 Oxygen consumption in critically-ill surgical patients. Ann Surg 176:801-8()4

4. Baker SP, O'Neill B, Haddon W, Long W 1974 The injury severity score: a method for describing patients with multiple injuries and evaluating emergency care. J Trauma 14:187-196

5. Teasdale G, Jennett B 1974 Assessment of coma and impaired consciousness. Lancet $2: 81-84$

6. James HE, Trauner DA 1985 The Glasgow Coma Scale. In: James HE, Anas NG, Perkin RM (eds) Brain Insults in Infants and Children. Grune \& Stratton, London, pp $179-182$

7. Berger MS, Pitts LII, Lovely M, Edwards MSB, Bartkowski HM 1985 Outcome from severe head injury in children and adolescents. J Neurosurg 62:194-199

8. Tasker RC, Matthew DJ, Helms P, Dinwiddic R, Boyd S 1988 Monitoring in non-traumatic coma. Part 1: Invasive intracranial measurements. Arch IDis Child 63:888- 894

9. Sharples PM, Stuart AG, Matthews DSF, Aynsley-Green A, Eyre JA 1995 Cerebral blood flow and metabolism in scverely head injured children. Part 1: Relationship to age, Glasgow coma score, outcome, intracranial pressure and time after injury. $J$ Neurol Neurosurg Psychiatry (in press)

10. Knauth A, Baumgart S 1990 Accurate noninvasive quantitation of expiratory gas leak from uncuffed infant endotracheal tubes. Pediatr Pulmonol 9:55-60

11. Mayfield SR 1991 Technical and clinical testing of a computerized indirect calorimeter for use in mechanically ventilated neonates. Am J Clin Nutr 54:30-34

12. Fleck $A$, Munro HN 1965 The determination of organic nitrogen in biological materials. A review. Clin Chim Acta 11:2-12

13. Weir JB 1949 New methods for calculating metabolic rate with special reference to protein metabolism. J Physiol (Lond) 109:1-9

14. Westenskow DR, Cutler CA, Wallace WD 1984 Instrumentation for monitoring gas exchange and metabolic rate in critically ill paticnts. Crit Care Med 12:183-187

15. Schofield WN 1985 Predicting basal metabolic rate, new standards and review of previous work. Hum Nutr Clin Nutr 39C:5-41

16. Schaefer F, Georgi M, Zieger A, Scharer K 1994 Usefulness of bioelectrical impedance and skinfold measurements in predicting fat-frec mass derived from total body potassium in children. Pediatr Res 35:617-624

17. Christofides ND 1982 Pancreatic glucagon. In: Bloom SR, Long R (cds) Radioimmunoassay of Gut Regulatory Peptides. WB Saunders, London, pp 74-79

18. Brown MJ, Jenner DA 1981 Novel double-isotope technique for enzymatic assay of catecholamines, permitting high precision, sensitivity and plasma sample capacity. Clin Sci 61:591-598

19. Goldstein H 1987 Multilevel Models in Educational and Social Research. Charles Griffìn \& Company, Oxford, UK

20. Prosser R, Rasbash J, Goldstein H 1991 ML3: software for three-level analysis. Institute of Education, London

21. Young DS 1987 Implementation of SI units for clinical laboratory data. Ann Intern Med 106:114-129

22. Ranke MB 1992 Functional Endocrinologic Diagnostics in Children and Adolescents J \& J Verlag, Mannheim, Germany

23. Little RA, Stoner HB, Frayn KN 1981 Substrate oxidation shortly after accidental injury in man. Clin Sci 61:789-791

24. Weissman C, Kemper M, Askanazi J, Hyman AI, Kinney JM 1986 Resting metabolic rate of the critically ill patient: measured versus predicted. Anesthesiology 64:673679 
25. Robertson CS, Clifton GL, Grossman RG 1984 Oxygen utilisation and cardiovascular function in head-injured patients. Neurosurgery 15:307-314

26. Phillips R, Ott L, Young B, Walsh J 1987 Nutritional support and measured energy expenditure of the child and adolescent with head injury. J Neurosurg 67:846-851

27. Bursztein S, Taitelman U, De Myttenaere S, Michelson M, Dahan E, Gepstein R, Edelman D 1978 Reduced oxygen consumption in calabolic states with mechanical ventilation. Crit Care Med 6:162-164

28. Rosen DA, Rosen KR 1991 Midazolam for sedation in the paediatric intensive care unit. Intensive Care Med 17:S15-S19

29. Takada Y, Yamaguchi T, Kiuchi T, Mori K, Shimahara Y, Kobayashi N, Yamaoka $Y 1991$ Effect of glucagon on hepatic energy charge and arterial ketone body ratio in normal rabbits. Gastroenterology 100:1041-1045

30. Grande F 1980 Energy expenditure of organs and tissues. In: Kinney JM (ed) Assessment of Energy Mctabolism in Health and Disease. Ross Laboratories, Columbus, $\mathrm{OH}$, pp $88-92$

31. Bessey PQ, Watters JM, Aoki TT, Wilmore DW 1984 Combined hormonal infusion simulates the metabolic response to injury. Ann Surg 200:264-281

32. Zucker $\Lambda$ R, Chernow B, Fields $\mathrm{Al}$, Hung W, Burman KD 1985 Thyroid function in critically ill children. J Pediatr 107:552-554
33. Kaptein EM, Weiner JM, Robinson WS, Wheeler WS, Nicoloff JT 1982 Relationship of altered thyroid hormone indices to survival in nonthyroidal illnesses. Clin Endocrinol 16:565-574

34. Oppenheimer JH 1985 Thyroid hormone action at the nuclear level. Ann Intern Med 102:374-384

35. Sterling K 1986 Direct thyroid hormone activation of mitochondria: the role of adenine nucleotide translocase. Endocrinology 119:292-295

36. Liggett SB, Raymond JR 1993 Pharmacology and molecular biology of adrencrgic receptors. Baillieres Clin Endocrinol Metab 7:279-306

37. Gross G, Brodde OE, Schumann HJ 1980 Effects of thyroid hormone deficiency on pre- and post-synaptic noradrenergic mechanisms in the rat cercbral cortex. Arch In Pharmacodyn Ther 244:219-230

38. Rosenbaum M, Presta E, Hirsch J, Leibel RL 1991 Regional differences in adrenoreceptor status of adipose tissuc in adults and prepubertal children. J Clin Endocrinol Metab 73:341-347

39. Sicgel JH, Cerra FB, Coleman B Giovannini I, Shetye M, Border JR, McMenamy RH 1979 Physiological and metabolic correlations in human sepsis. Surgery 86:163-193

40. Hadficld JM, Little RA, Jones RAC 1992 Measured energy expenditure and plasma substrate and hormonal changes after severe head injury. Injury 23:177-182 